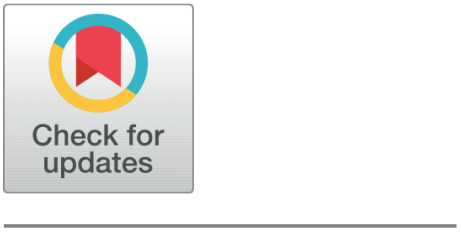

OPEn ACCESS

Received: 17.05.2020

Accepted: 04.01.2021

Published: 28.01 .2021

Citation: Loñez HE, Banwa TP (2021) Butterfly Pea (Clitoria ternatea): A natural colorant for soft candy (Gummy Candy). Indian Journal of Science and Technology 14(3): 239-244. https://doi.org/ 10.17485/IJST/v14i3.582

* Corresponding author.

Tel: 0912-944-2612

henrilynestoque29@gmail.com

Funding: Kalinga State University

Competing Interests: None

Copyright: (c) 2021 Loñez \& Banwa. This is an open access article distributed under the terms of the Creative Commons Attribution License, which permits unrestricted use, distribution, and reproduction in any medium, provided the original author and source are credited.

Published By Indian Society for Education and Environment (iSee)

ISSN

Print: 0974-6846

Electronic: 0974-5645

\section{Butterfly Pea (Clitoria ternatea): A natural colorant for soft candy (Gummy Candy)}

\author{
Henrilyn E. Loñez ${ }^{1 *}$, Tules P Banwa² \\ 1 Faculty Member, College of Education, Kalinga State University, Bulanao, Tabuk City, \\ Kalinga, 3800, Philippines. Tel.: 0912-944-2612 \\ 2 Professor, College of Health and Natural Sciences, Kalinga State University, Bulanao, Tabuk \\ City, Kalinga, 3800, Philippines
}

\section{Abstract}

Background/Objectives: The utilization of natural colorant can improve food appeal. This study determined the potential of Clitoria ternatea flower extract as a substitute for synthetic colorants. Methods: The researchers prepared gummy candies using $100 \mathrm{~mL}$ aqueous extracts from various weight samples of C. ternatea flowers. Fifty candy eaters with different age brackets were randomly chosen as respondents of this study. The respondents evaluated through the sensorial method the different treatments in terms of taste, texture, color, smell, appearance, and overall palatability using a nine-point scale hedonic scale. The researchers compared the age brackets using the analysis of variance. Findings: Results showed that aqueous extract of Treatment 3 (30 grams) has the highest total weighted average mean (TAWM) of 7.78 level of acceptability with a "Like Very Much" description, followed by the TAWM of 6.57 of Treatment 4 ( 40 grams) with "Moderately Like" description. In comparison, Treatment 1 (10 grams) has the lowest TAWM of 2.97 with a description of "Dislike Moderately." The high level of acceptability implies that $C$. ternatea flower aqueous extract improves the color and appearance of the gummy candies. This study further shows no significant difference in acceptability among the respondents when grouped into age brackets. The researchers conclude that the aqueous flower extract of $30 \mathrm{~g} \mathrm{C}$. ternatea improved the color and appearance of the gummy candies. Furthermore, it could be accepted by the candy consuming public of various ages. Novelty/Applications (30): The utilization of $C$. ternatea flower aqueous extract as a colorant improves the acceptability of commercial gummy candies. The use of alternative safe, natural colorants promotes healthy living and sustainable candy production.

Keywords: Clitoria ternatea; gummy candies; level of acceptability; sensorial method; hedonic scale 


\section{Introduction}

The use of food colorant in food products is vital in increasing product appeal ${ }^{(1)}$. Food colorants are divided into natural and synthetic food colors. Natural food color is derived from various sources such as seeds, fruits, vegetables, insects, and microorganisms without any chemical treatment ${ }^{(2)}$. Synthetic food colorant is water-soluble substances that have been made in a factory and used in foods without any further processing ${ }^{(3)}$. Artificial food colors are reliable and economical for restoring the original appearance of the foods compared to the natural colorants, which are expensive and less stable ${ }^{(4)}$. However, in several cases, food colorants have been misused to conceal lousy quality. Studies linked the consumption of artificial dye to the harmful effect and hyperactivity in children ${ }^{(5)}$. The synthetic food colorants showed an adverse effect on human health. Consumption of synthetic food color additives could sometimes lead to toxic effects on the liver, kidney, and testes ${ }^{(6)}$. Synthetic additive usage and synthetic food colors resulted in today's food trend, where everything natural is considered a healthier option. Some alternative to synthetic colors includes anthocyanins, betacyanins, lycopene, turmeric, and chlorophyll ${ }^{(1)}$. One of the most available natural blue sources is the C. ternatea flower or Pokindang in the Philippines. The flower contains more than nine types of anthocyanins, which provide the red-purple-blue hues on the extracted pigment.

The food industry traditionally used blue dye aqueous extract from the petal of butterfly pea as a confectionary coloring ${ }^{(7)}$ and natural colorant for drinks ${ }^{(7)}$.

C. ternatea originates in Southeast Asia. This perennial plant is erect, with elliptic and obtuse leaves. It grows up 90 to 162 $\mathrm{cm}$ as a vine or creeper, doing well in moist, neutral soil ${ }^{(8)}$. It belongs to the family Fabaceae and has various names. C. ternatea is called pokindang in the Philippines. It has various names such as Asian pigeon wings, bluebell vine, blue pea, butterfly pea, Darwin pea, as telang (Malaysia), Kordofan pea (Sudan), and Cunha (Brazil) ${ }^{(9)}$.

C. ternatea has solitary flowers with vivid, deep-blue, and white coloration. The flowers are 6 to $12 \mathrm{~cm}$ long. Furthermore, it contains 6 to 8 brown or black colored seeds per pod, which are slightly pubescent or glabrous ${ }^{(9,10)}$. The flower of C. ternatea appears like a conch-shell that is said to be suitable for the treatment of mental illness ${ }^{(11)}$. Butterfly pea flower has high amounts of anthocyanin pigments.

Water-soluble anthocyanins are essential in research. They impart beautiful coloration to food systems and have antioxidant properties and health benefits. These benefits include sight enhancement, antioxidant properties, controlling Type II diabetes, reduction of coronary heart disease, and prevention of cancer ${ }^{(12)}$.

Anthocyanin pigment from C. ternatea has anti-viral and anti-inflammatory properties. Besides, this pigment is antioxidant, anti-allergic, and anti-microbial properties. Further, anthocyanin prevents diabetes, protects the cardiovascular system from damage, and many more health benefits ${ }^{(13)}$. Moreover, research findings suggested that anthocyanin helps in protecting the cell as an anti-aging agent, protects cell damage, and promoting healthy eyes ${ }^{(14)}$.

Experimental results indicate that $C$. ternatea to be rich in antioxidant properties compared to other flowers and medicine elements. In ancient human civilization, C. ternatea has been used to treat neurological disorders ${ }^{(15)}$. Besides, C. ternatea shows promising effects as having antioxidant, can cure diabetic and hepatoprotective activities ${ }^{(16)}$. The significant phytoconstituents analyzed in C. ternatea are flavonoids, phlorotannins, reducing sugars, and carbohydrates. Other published researches reported the medicinal effects of $C$. ternatea, such as antipyretic, analgesic, and anti-inflammatory ${ }^{(17)}$. These properties are good for one's health and well-being because they help to reduce health disorders.

The antioxidant activity of the aqueous extractions of $C$. ternatea flowers showed a much higher scavenging activity than methanol-based extracts ${ }^{(18)}$. When the concentrations of extracts increased, the extracts' percentage to scavenge off free radicals also increased ${ }^{(19)}$.

Researchers conducted studies and found out that $C$. ternatea flowers can be used as natural substances to reduce blood glucose levels. Researchers administered $150 \mathrm{mg} / \mathrm{kg}$ of $C$. ternatea flower extract per $\mathrm{kg}$ body weight of diabetic rats ${ }^{(20)}$. They reported a significant decrease in glucose level after 14 days. Moreover, a rat treated with $C$. ternatea flower extracts showed improvement against the hyperglycemic and hyperlipidaemic. These properties can prevent liver and renal damage.

Butterfly pea flower plays an essential role in nervine medicine by improving the brain system ${ }^{(21)}$. Further, the whole plant has medical value. The flower juice extract of $C$. ternatea can cure skin diseases and insect stings ${ }^{(22)}$

Proximate and mineral analysis of C. ternatea flowers contained calcium $(3.10 \mathrm{mg} / \mathrm{g})$, magnesium $(2.23 \mathrm{mg} / \mathrm{g})$, and potassium $(1.25 \mathrm{mg} / \mathrm{g})^{(23)}$. The major constituents found in C. ternatea were flavonoids, anthocyanins, alkaloids, ternatins, saponins, tannins, taraxerol, and taraxerone. Spectroscopy analysis showed that C. ternatea had 14 types of flavonol glycosides ${ }^{(24)}$. Moreover, C. ternatea contains kaempferol 3-glucoside, quercetin 3-glucoside, and myricetin 3-glucoside.

Natural dye from C. ternatea could be a coloring agent for making products ${ }^{(14)}$. In countries like China and Malaysia, people used C. ternatea flowers for making blue colored tea and blue rice. This edible natural colorant can be used in any food compound, replacing synthetic colorants in color, taste, and cost economy ${ }^{(25)}$. Moreover, anti-pollution and biodiversity 
policies imposed environmental standards in response to allergic reactions and toxin in the synthetic dye.

Nowadays, natural candies with high antioxidant properties and medicinal properties are not commercially available at low cost. Antioxidant enriched food products are many, but candies with free radical scavenging activity are rarely found ${ }^{(25)}$. Candy equally attracts children and adult age people.

Candy has little nutritional value. Historically, when malnutrition was severe at the onset of the 20th century, the highcalorie content of candies was promoted as a virtue among the poor and working-class people. Researchers suggested that candy, especially candy with milk and nuts, was a low-cost alternative to healthy meals ${ }^{(26)}$. In this study, the researchers added gelatin to make the candy gummier and more appetizing to consumers of all ages. Gummy candies are made with a gelatin base and are often flavored with fruit juice extracts. Gelatin gives a distinctive chewy texture that ranges from soft to very firm, depending on the gelatin amount used. Gelatin is a thickening agent similar to agar-agar. However, it has made from the collagen found in animal skin and bones.

Food attributes depend on sensory evaluations. One of these attributes is food texture. Texture evaluation is affected by age ${ }^{(27)}$. Another visual food attribute is color. Food color is known to affect food evaluation, and it varies according to age ${ }^{(28)}$. Generally, the appearance of foods includes color and texture ${ }^{(29)}$. Aside from these, taste and overall food palatability depends on the ingredients of the food product.

This study determined the potential of using the Butterfly pea flower extract as a substitute for synthetic colorant to soft candy. This study determined the level of acceptability of the different treatments by the respondents. It further determined if there was a significant difference in the level of acceptability of the treatments of the respondents when grouped according to age profile.

\section{Materials and Methods}

The researchers conducted the study in selected areas of Tabuk City, Kalinga, Philippines, and used the descriptive method in this study. They determined the level of acceptability of the treatments through sensorial evaluation with questionnaires.

The researchers selected the respondents randomly from the general public who ate candies. Then the researchers grouped the respondents based on their age brackets with ten years range. The lowest age bracket of candy caters who can respond to the survey was 6-15 years old, followed by 16-25 years old, 26-35 years old, 36-45 years old, and 46 years old and above. The researchers chose the first ten interested candy eaters as respondents in the five age brackets. A total of 50 respondents participated in this study.

The respondents evaluated the different treatments using the 9-point hedonic scale with a range of descriptions of "like extremely" to "dislike extremely," adopted from the work of Peryam ${ }^{(30)}$.

\subsection{Preparation and sensorial evaluation of gummy candy samples}

The preparation of gummy candy samples followed the following flow-chart.
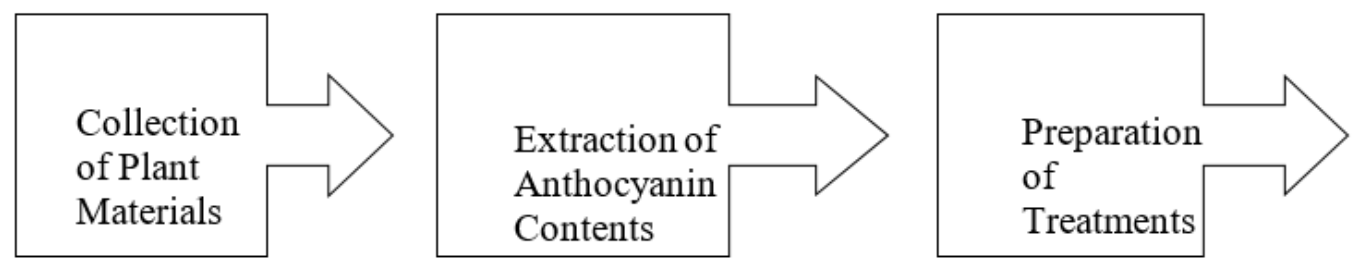

Sensory

Evaluation of

Treatments by

Respondents

\subsubsection{Collection of plant materials}

The researchers collected fresh Butterfly Pea Flowers (C. ternatea) from home gardens. The individual flower, without defects and diseases, was selected and de-stemmed. The researchers stored samples at $4{ }^{\circ} \mathrm{C}$ using a standard refrigerator before the experiment, which was not more than three days after the harvest. The aqueous extraction of $C$. ternatea flowers was carried according to the procedure of Kuntapas Kungsuwan ${ }^{(31)}$. 


\subsubsection{Extraction of anthocyanin contents}

The researchers performed the aqueous extraction method in this study. This extraction method minimizes contamination from the chemical and harmful substances. Different amounts of $C$. ternatea flowers mixed with $1000 \mathrm{~mL}$ distilled water were used as treatments. These treatments were as follows; Treatment $1(\mathrm{~T} 1)=10 \mathrm{~g}$ C. ternatea flowers, $\mathrm{T} 2=20 \mathrm{~g}$ C. ternatea, $\mathrm{T} 3=30 \mathrm{~g}$ C. ternatea, and $\mathrm{T} 4=40 \mathrm{~g} \mathrm{C}$. ternatea. The researchers separately extracted the natural dyes from the different treatments. The process started with submerging the different treatments in $1000 \mathrm{~mL}$ of water for 30 minutes. Then, the researchers mixed the C. ternatea flowers and distilled water using a commercial blender for 30 seconds. Moreover, the resulting mixture was filtered through 2 layers of cheesecloths to get the crude extracts of the treatments.

\subsubsection{Preparation of gummy candy}

The resultant crude extracts of the different treatments were separately mixed with 6tbsp Ferna Gelatin, 6tbsp raw honey, and 6tbsp lemon juice to prepare gummy candy. In a small saucepan, combine lemon juice and honey over medium-low heat using a whisk to stir the mixture. The researchers added gelatin into the mixture with constant stirring. Avoid dumping the gelatin at once because it could cause big globs formation that affects the product.

The crude extract of the treatment was added to the mixture, and heating was continued over medium-low heat until all ingredients were mixed thoroughly. The gelatin was completely melted. Well-melted gelatin would change from a grainy, jellylike consistency to a glassier, smooth consistency.

The mixture was poured into a gummy candy molder and placed in the freezer for about 2 hours to firm up. The gummy candies were removed from the freezer and popped from the molders, and stored in airtight containers. Then we kept in refrigerators for up to 2 weeks. The researcher used the same procedure in preparing different treatments. The gummy candies prepared from the different treatments served experimental gummy candies. Meanwhile, the researchers used a commercial candy as a control treatment.

\subsubsection{Sensory evaluation}

Sensory evaluation offered the opportunity to obtain a complete analysis of the various properties of food as perceived by the human sense. The evaluation was an important and best method for evaluating new products developed, which provide a quality measure and production control. The respondents sensory evaluated the treatments using a hedonic (9 point) scorecard.

Every respondent evaluated a set of sampling products of gummy candies for taste-testing and rating scales. The taste parameters evaluated included the taste, texture, color, smell, appearance, and overall palatability of the products. We arranged the treatments in a completely randomized design (CRD).

In between testing samples, they were given apple slices as one of the great and most available palate cleansers. The apple helped distinguish flavors between the products when testing and will not affect the results.

\subsubsection{Statistical analysis}

The data were analyzed and interpreted using weighted means and ranking. The Analysis of Variance (ANOVA) was used to find significant differences in the acceptability of the treatments as to age brackets. SPSS version 16 was used to analyze the data.

\section{Results and Discussion}

\subsection{Level of acceptability of the different treatments based on different sensorial parameters}

Table 1 shows that T3 ranks 1st among the treatments with an average weighted mean of 7.78, followed by T4 with 6.57. Treatment 1 ranks $5^{\text {th }}$ with the lowest weighted mean of 2.97 . The result shows that the incorporating $30 \mathrm{~g}$ of $C$. ternatea petals in gummy candy could improve the taste, texture, color, smell, appearance, and overall palatability of the experimental treatment. The high total weighted mean indicates improvement.

Treatment 1 (T1) has a level of acceptability total average weighted mean of 2.97 with a description of "Dislike Moderately." The result shows that the respondents moderately dislike T1. The minimum amount of $10 \mathrm{~g}$ of $C$. ternatea petals could have affected the taste, texture, color, smell, appearance, and overall palatability of gummy candies. The color has a mean of 2.33 with a "Dislike Very Much" description. This result shows that the gummy candies' color with $10 \mathrm{~g}$ C. ternatea petals is not attractive to the respondents.

Treatment 2 (T2) shows a total weighted average mean of 5.90 with a "Like SLightly" description. It indicates that as the amount of C. ternatea petals increased from $10 \mathrm{~g}$ to $20 \mathrm{~g}$, there is an increase in the weighted average mean from 2.97 to 5.90 .

The respondents' sensory evaluation weighted mean increased to 7.78 with the "Like Very Much" description in T3. The increase implies that $30 \mathrm{~g} \mathrm{C}$. ternatea flower petals improved the acceptability of experimental gummy candies. The color 
acceptance of the gummy candy increases to a weighted mean of 8.22 with a "Like Extremely" description.

Increasing the amount of $C$. ternatea flower petals to $40 \mathrm{~g}$ seems to lessen the gummy candies' acceptability to the respondents. The respondents' taste, texture, and smell on T4 are "Like Slightly." Meanwhile, the appearance and overall palatability of T4 have a "Like Moderately" description. Further, T4 shows the highest weighted mean of 8.06 in terms of color with a "Like Very Much" description. The result shows that a higher amount of pigment extract increases the gummy candies' attractiveness but decreases the acceptability of the tastes, texture, and smell of gummy candies.

The researchers used a commercial candy (Gummy Series) as a control treatment (T5) in this study. Table 1 shows that T5 has the lowest weighted mean of 2.30 for texture and the highest weighted mean of 3.90 for an appearance with "Dislike Very Much" and "Dislike Slightly" descriptions. Meanwhile, T5 has a total average weighted mean of 3.07 with a "Dislike Moderately" description.

Table 1. Comparison of the weighted means of the parameters of different treatments

\begin{tabular}{|c|c|c|c|c|c|c|c|c|c|}
\hline \multirow{2}{*}{ Treatments } & \multicolumn{6}{|c|}{ Parameters } & \multirow{2}{*}{ TAWM } & \multirow[b]{2}{*}{ Description } & \multirow{2}{*}{ Rank } \\
\hline & Taste & Texture & Color & Smell & Appearance & $\begin{array}{l}\text { Overall Palatabil- } \\
\text { ity }\end{array}$ & & & \\
\hline $\mathrm{T} 1$ & 3.48 & 3.40 & 2.33 & 2.88 & 2.90 & 2.80 & 2.97 & $\mathrm{DM}$ & 5 \\
\hline $\mathrm{T} 2$ & 6.00 & 5.94 & 5.59 & 6.08 & 5.56 & 6.20 & 5.90 & LS & 3 \\
\hline $\mathrm{T} 3$ & 7.70 & 7.62 & 8.22 & 7.66 & 7.70 & 7.82 & 7.78 & LVM & 1 \\
\hline $\mathrm{T} 4$ & 6.02 & 6.16 & 8.06 & 6.20 & 6.42 & 6.40 & 6.57 & $\mathrm{LM}$ & 2 \\
\hline T5 & 2.86 & 2.30 & 3.06 & 3.18 & 3.90 & 3.12 & 3.07 & $\mathrm{DM}$ & 4 \\
\hline
\end{tabular}

Legends: TAWM-totalaverage weighted mean, DM-dislike moderately, LS-like slightly,

LVM-like very much, LM-like moderately

\subsection{Mean difference of the level of acceptability of the treatments by the respondents when grouped to age-brackets}

The researchers compared the level of acceptability among the different age brackets of the respondents (Table 2).

Table 2. Mean difference in the acceptability of the gummy candy by respondents when grouped according to age brackets.

\begin{tabular}{|c|c|c|c|c|}
\hline Age bracket (years) & Total Average Weighted Mean & F-computed & F-crit & Probability \\
\hline $06-15$ & 5.3148 & $.011^{\mathrm{ns}}$ & 2.866081 & 0.999753 \\
\hline $16-25$ & 5.3600 & & & \\
\hline $26-35$ & 5.1067 & & & \\
\hline $36-45$ & 5.3200 & & & \\
\hline 46 above & 5.2171 & & & \\
\hline
\end{tabular}

ns= no significant difference

Table 2 shows a computed F-value of 0.011 , which is lower than the critical value of 2.866 with a probability of 0.999 . This finding indicates no significant difference in the level of acceptance of the respondents when grouped into age brackets. This result shows that the level of acceptability of the treatments by respondents six years and above does not differ significantly. This finding means the gummy candy product with C. ternatea colorant is acceptable to children and adults.

\section{Conclusion}

The aqueous flower extract of $30 \mathrm{~g}$ C. ternatea improved the color and appearance of the gummy candies, thus resulting in a higher level of acceptability. This study shows that the gummy candies with C. ternatea flower colorant are acceptable to consumers aging six years and above.

\section{Acknowledgment}

The researchers acknowledge the panel of evaluators from the Cordillera Consortium for Agriculture Aquatic and Resources Research and Development (CorCAARRD) for their inputs and Kalinga State University for the support. 


\section{References}

1) Wrolstad RE, Culver CA. Alternatives to Those Artificial FD\&C Food Colorants. Annual Review of Food Science and Technology. 2012;3:59-77. Available from: https://dx.doi.org/10.1146/annurev-food-022811-101118.

2) Saxena S, Raja ASM. Natural dyes: sources, chemistry, application, and sustainability issues. and others, editor;Springer. $2014 . \quad$ Available from: https://link.springer.com/chapter/10.1007/978-981-287-065-0_2.

3) Tripathi M, Khanna S, Das M. Surveillance on use of synthetic colours in eatables vis a vis Prevention of Food Adulteration Act of India. Elsevier. 2007. Available from: https://www.sciencedirect.com/science/article/pii/S0956713505002264.

4) Saleem N, Umar ZN, khan SI. Survey on the use of synthetic Food Colors in Food Samples procured from different educational institutes of Karachi city. Journal of Tropical Life Science. 2013;3(1):1-7. Available from: https://dx.doi.org/10.11594/jtls.03.01.01.

5) Potera C. DIET AND NUTRITION: The Artificial Food Dye Blues. Environ Health Perspect. Internet]. 2010;118(10). Available from: https://ehp.niehs. nih.gov/doi/10.1289/ehp.118-a428.

6) Sangam S, Naveed A, Athar M, Prathyusha P, Moulika S, Lakshmi S. Evaluation of Toxicity of Synthetic Food Colors on Human Normal Flora and Yeast. Int J Heal Sci Res [Internet]. 2015;5(1):156-164. Available from: https://www.ijhsr.org/IJHSR_Vol.7_Issue.8_Aug2017/17.pdf.

7) Tantituvanont A, Werawatganone P, Jiamchaisri P, Manopakdee K. Preparation and stability of butterfly pea color extract loaded in microparticles prepared by spray drying. Thai J Pharm Sci. 2008;32:59-69. Available from: http://www.thaiscience.info/journals/Article/TJPS/10576402.pdf.

8) Karel A, Kumar H, Chowdhary B. Clitoria ternatea L. A Miraculous Plant. International Journal of Current Microbiology and Applied Sciences. 2018;7(09):672-674. Available from: https://dx.doi.org/10.20546/ijcmas.2018.709.079.

9) Kalamani A, Gomez SM. Genetic variability in Clitoria spp. Ann Agric Res. 2001;22(2):243-248. Available from: https:/eurekamag.com/research/003/ 784/003784280.php.

10) Gomez SM, Kalamani A. Butterfly Pea (Clitoria ternatea): A Nutritive Multipurpose Forage Legume for the Tropics - An Overview. Pakistan Journal of Nutrition. 2003;2(6):374-379. Available from: https://dx.doi.org/10.3923/pjn.2003.374.379.

11) Daisy P, Santosh K, Rajathi M, College HC, Tamilnadu T. Antihyperglycemic and antihyperlipidemic effects of Clitoria ternatea Linn. in alloxan-induced diabetic rats. African J Microbiol Res. 2009;3(5):287-91. Available from: http://www.academicjournals.org/ajmr.

12) Bagchi D, Sen CK, Bagchi M, Atalay M. Anti-angiogenic, Antioxidant, and Anti-carcinogenic Properties of a Novel Anthocyanin-Rich Berry Extract Formula. Biochemistry (Moscow). 2004;69(1):75-80. Available from: https://dx.doi.org/10.1023/b:biry.0000016355.19999.93.

13) Ghosh D, Konishi T. Anthocyanins, and anthocyanin-rich extracts.pdf. Asia Pac J Clin Nutr. 2007;16(2):200-208.

14) Jamil N, Zairi M, N M, Nasim M, A N, ' P. Influences of Environmental Conditions to Phytoconstituents in Clitoria ternatea (Butterfly Pea Flower) - A Review. J Sci Technol [Internet]. 2018;10(2):208-228. Available from: https://pdfs.semanticscholar.org/0e06/8330ec007c8da63608f4956525a8ea2ecb24. pdf.

15) Khadatkar SN, Manwar JV, Bhajipale NS. In-vitro anthelmintic activity of root of Clitoria ternatea Linn. Pharmacognosy Magazine [Internet]. 2008;4(13):148-150. Available from: http://www.phcog.com/article.asp?issn=0973-1296; year=2008; volume=4;issue=13; ;page =148; epage=150;aulast= Khadatkar:type $=0$.

16) Zingare ML, Zingare PL, Dubey AK. Clitoria ternatea(APARAJITA): A review of the antioxidant, antidiabetic and hepatoprotective potentials. International J Pharm Biol Sci [Internet]. 2013;3(1):203-213. Available from: https://www.ijpbs.com/ijpbsadmin/upload/ijpbs_510e88f33323f.pdf.

17) Mukherjee PK, Kumar V, Kumar NS, Heinrich M. The Ayurvedic medicine Clitoria ternatea-From traditional use to scientific assessment. Journal of Ethnopharmacology. 2008;120(3):291-301. Available from: https://dx.doi.org/10.1016/j.jep.2008.09.009.

18) Rabeta M, Nabil A. Total phenolic compounds and scavenging activity in Clitoria ternatea and Vitex negundo Linn. Int Food Res J. 2013;20(1):495-500. Available from: https://cutt.ly/Zj87fOO.

19) Ramaswamy V, Varghese N, Simon A. An investigation on Cytotoxic and Antioxidant properties of Clitoria Ternatea L. Int J Drug Discov. $2011 ; 3(1): 74-77$. Available from: https://pdfs.semanticscholar.org/aec3/dc87bd4cc8423d812adb076cd000db279813.pdf.

20) Gunjan M, G J. International Journal of Pharmacognostic and antidiabetic study of Clitoria ternatea. Int J Phytomedicine. 2010;2:373-378. Available from: https://www.researchgate.net/publication/265321466_Pharmacognostic_and_antidiabetic_study_of_Clitoria_ternatea.

21) Sethiya N, Nahata A, Xue SM, Dixit V. An update on Shankhpushpi, a cognition-boosting Ayurvedic medicine. 2009. Available from: https://cutt.ly/ Yj87OOD.

22) Agrawal P, Deshmukh S, Ali A, Patil S, Magdum S, Mohite S. Wildflowers as medicine. Int J GREEN Pharm. 2007. Available from: http://greenpharmacy. info/index.php/ijgp/article/view/403/425.

23) Neda G, Rabeta M, Ong M. Chemical composition and anti-proliferative properties of flowers of Clitoria Ternatea. Food Res J [Internet. 2013;20(3):12291234. Available from: https://cutt.ly/Ej87LF5.

24) Kazuma K. Malonylated flavonol glycosides from the petals of Clitoria ternatea. Phytochemistry. 2003;62(2):229-237. Available from: https://dx.doi.org/ 10.1016/s0031-9422(02)00486-7.

25) Caroline A, Padmavati R. Evaluation of $\mathrm{C}$. Ternatea Extract and Incorporation into Hard Candy. Int J Latest Technol Eng Manag Appl Sci [Internet]. 2015;IV:72-76. Available from: https://www.academia.edu/11475072/Evaluation_of_C._Ternatea_Extract_and_Incorporation_into_Hard_Candy.

26) Achumi L, Peter E, Das OA. Studies on preparation of gummy candy using pineapple juice and carrot juice. Int J Chem Stud. 2018;6(5):1015-1018. Available from: http://www.chemijournal.com/archives/2018/vol6issue5/PartR/6-4-746-393.pdf.

27) Szczesniak AS. Texture is a sensory property. Food Quality and Preference. 2002;13(4):215-225. Available from: https://dx.doi.org/10.1016/s0950-3293(01) 00039-8.

28) Clydesdale FM. Color as a factor in food choice. Critical Reviews in Food Science and Nutrition. 1993;33(1):83-101. Available from: https://dx.doi.org/ $10.1080 / 10408399309527614$.

29) Imram N. The role of visual cues in consumer perception and acceptance of a food product. Nutrition \& Food Science. 1999;99(5):224-230. Available from: https://dx.doi.org/10.1108/00346659910277650.

30) Peryam DR. The 9-Point Hedonic Scale. Peryam \& Kroll Research Corporation. 1998. Available from: https://www.sensorysociety.org/knowledge/sspwiki/ Pages/The9-pointHedonicScale.aspx.

31) Kungsuwan K, Singh K, Phetkao S, Utama-Ang N. Effects of $\mathrm{pH}$ and anthocyanin concentration on color and antioxidant activity of Clitoria ternatea extract. Food Appl Biosci J [Internet]. 2014;2(1):31-46. Available from: https://li01.tci-thaijo.org/index.php/fabjournal/article/view/77397/62086. 